\title{
Healthy happiness: effects of happiness on physical health and the consequences for preventive health care
}

\section{R. Veenhoven}

Published online: 28 February 2007

(C) Springer Science+Business Media B.V. 2007

\begin{abstract}
Is happiness good for your health? This common notion is tested in a synthetic analysis of 30 follow-up studies on happiness and longevity. It appears that happiness does not predict longevity in sick populations, but that it does predict longevity among healthy populations So, happiness does not cure illness but it does protect against becoming ill. The effect of happiness on longevity in healthy populations is remarkably strong. The size of the effect is comparable to that of smoking or not.

If so, public health can also be promoted by policies that aim at greater happiness of a greater number. That can be done by strengthening individual life-abilities and by improving the livability of the social environment. Some policies are proposed. Both ways of promoting health through happiness require more research on conditions for happiness.
\end{abstract}

Keywords Happiness · Life satisfaction · Longevity · Public health · Social policy $\cdot$ Research synthesis

\section{The issue}

It is widely acknowledged that mental factors may influence physical functioning and that psychological well-being works positively on physical health. This idea does not

This study was done for ZonMw, the Netherlands' organization for health research and development and reported in Dutch in Veenhoven 2006a.

Earlier versions of this paper were presented at the 3rd European Conference on Positive Psychology in Braga, Portugal, July 3-6, 2006 and the 7th conference of the International Society for Quality of Life Studies, in Grahamstown, South Africa, July 16-20

R. Veenhoven $(\bowtie)$

Department of Social Sciences, Erasmus University Rotterdam, Postbus 1738, Rotterdam 3000

DR, Netherlands

e-mail: veenhoven@fsw.eur.nl 
only live among adherents of holistic medicine, it also has a firm root in academic psychology. There is good evidence for the negative effects of mental distress on physical health, e.g. of depression, anxiety and hostility and there are also indications for the beneficial effects of positive mental states, such as positive affect (Zautra, 2003).

In this context it is commonly assumed that happiness is conducive to physical health. It is believed that happiness helps to heal the sick and that it protects people in good healthy against getting ill. In this view, health-care should not only be concerned with illness, it should also be concerned with wider quality-of-life. This view is reflected in broad definitions of health, such as the World Health Organization's definition of health as a state of general physical, mental and social wellbeing and not only the absence of illness and defect (Seedhouse, 1996, p. 41). In this line it is also asserted that current health education may be counter productive because it puts a damper on enjoyable things such as smoking and drinking (Warburton, 1994, 1996).

Yet there are also different notes. For instance, VanDam (1989) argues that positive attitudes cannot stop serious illness and that the idea of 'fighting cancer' with happiness is a mere illusion that blames the victim. Several studies have indeed failed to find longer survival times among happy cancer patients and some studies even report shorter survival times (e.g. Derogatis, Abeloff, \& Melisaratos, 1979). There is also doubt about the protective effect of happiness and even reports of greater mortality among cheerful people as a result to their more risky lifestyles (Friedman et al., 1993). In this view healthcare is better limited to physical health in the strict sense with too buoyant living being discouraged.

In this paper I address this issue in two ways: First I take stock of the empirical research on effects of happiness on physical health. I focus on longevity and assess whether happy people live longer. This appears to be the case, though happiness does not cure serious illness, it does appear to protect against falling ill in some way. Having established that happiness adds to health, I next explore the consequences of this finding for public health policy.

\section{Effects of happiness on physical health: A review of the research literature}

Assessing the effect of happiness on health requires first of all that we clearly define these concepts. The terms 'happiness' and 'health' are both used with different meanings, some of which overlap. Evidently we can assess meaningful effects only if we deal with different things. A second requirement is selection of appropriate measures of these concepts.

Happiness is defined, as the overall appreciation of one's life-as-a-whole, in short, how much one likes the life one lives. Elsewhere I have delineated that concept in more detail (Veenhoven, 1984, chapter 2). Thus defined, happiness is a state of mind and can therefore be measured using questioning techniques, among which single, direct questions. Self-reports of happiness appear to be fairly valid, though not very precise (Veenhoven, 1984, chapter 3).

As for the concept of health, I restrict to physical health, which I define in the narrow sense of absence of illness or defect. I do so to avoid conceptual overlap with happiness or related attitudinal matters. Physical health can be measured objectively 
using medical assessments or subjectively using self-reports. The most objective measure of physical health is longevity ${ }^{1}$.

\subsection{Correlational studies}

There is a wealth of cross-sectional studies on happiness and physical health, much of which is summarized in the World Database of Happiness, section Correlational findings on happiness and Physical Health (Veenhoven, 2006b). This research shows consistent positive relationships.

Correlations vary between +.10 and +.40 and appear to be largely independent of age, gender, socio-economic status and personality. The correlations tend to be higher in patient populations than among the general public. The correlations of happiness with self-rated health are somewhat stronger than the correlations between happiness and heath ratings based on medical examinations, but that does not necessarily mean that the relation with 'real health' is weaker, since objective indicators do not capture several relevant aspects of health (Benyamini, Leventhal, \& Leventhal, 1999). A recent cross national survey found highly similar correlations in 46 nations, a one point difference on the 5-step self-rating of health corresponding to a 0.6 point difference in happiness (Helliwel, 2002, p. 339).

These studies clearly show that there is a statistical relationship, but they do not inform us about cause and effect. The correlations can be caused by the effect of health on happiness rather than by effects of happiness of health. To disentangle cause and effect we need follow-up studies.

\subsection{Follow-up studies on effect of health on happiness}

Only four studies have been done to assess the effect of earlier physical health on later happiness. One of these estimated physical health in the first year of life, using the medical records of a maternity clinic, and found no statistical relation with happiness at age 33 (Ventegodt, 1997, p. 300). Likewise, a 12-year follow-up of adults did not find a correlation between doctor's visits at baseline and later happiness (Chiriboga, 1982, p. 23). Another 12-year follow-up of middle aged Americans did find some relation between baseline self-rated health and later happiness, but no effect of change in physical health over this period (Palmore, 1977, p. 315). Still another 12-year follow-up among married couples in the USA found a small correlation between baseline self-rated health and later happiness $(r=+.13 p<.001)$. Interestingly, this study also observed a stronger effect of baseline happiness on later health $(r=+.37 p<.001$, Hawkins \& Booth, 2005, p. 456). These results suggest that the observed correlation between happiness and health will be largely due to a causal effect of happiness, and as we will see, that is the case.

\subsection{Follow-up studies on effect of happiness on health, in particular longevity}

Physical health can be measured objectively using medical assessments or subjectively using self-reports. For the purpose of this study I opted for the most objective measure possible, that is, longevity. The reason was to avoid contamination. If we

\footnotetext{
${ }^{1}$ No measure of health is perfect. Longevity does not capture the good health of people who dye prematurely as a result of an accident.
} 
measure health using self-reports, there would be a fair chance that happiness colors self-appraisals of health and this could even be the case with medical assessments that are at least partly based on reports of symptoms.

Studies There is a lot of research on predictors of longevity. Studies at the individual level have documented effects of various genetic factors, physical functioning, personality traits, life style variables, social support and socio-economic status. For a recent review see Lyyra (2006). Only some of these studies have involved indicators of happiness and because happiness is typically a side issue it is difficult to trace the findings bibliographically. Most references were found in the Bibliography of the World Database of Happiness (Veenhoven, 2006b) and in a recent monograph on the consequences of subjective wellbeing by Lyubomirsky, Diener, and King (2005)

Selection I used three criteria for selecting studies: first that the investigation involved follow-up over time, second that longevity was assessed and third that this was related to earlier happiness. In the context of the latter criterion I inspected whether the indicators of happiness used fit the above definition of happiness. Some studies claim to assess happiness, but measured something else. This was for instance the case with the above-mentioned study that observed greater mortality among cheerful people, the word 'cheerfulness' being used for a happy-go-lucky attitude (Friedman et al., 1993).

Altogether, I found 30 studies, which gave a rather mixed bag. The studies were all done among different populations and used different methodologies. A main methodological difference was found in the control variables. Some of the studies did not assess baseline physical health and could therefore not rule out the possibility that greater longevity of the initially most happy is due to their better initial physical health. Most studies did control baseline physical health, but assessed this in different ways, some using self-reports and others medical screening. Another noteworthy difference was in the statistics used for quantifying the effect of happiness on longevity. Some studies expressed the difference in a regression coefficient and others in Odds Ratio's of different kinds. On the basis of the published research reports I could not transform the findings to obtain a common effect size and a full blown meta-analysis is therefore not possible.

Results Together, researchers in these 30 studies observed 38 effects, with some researchers looking at subgroups separately. In 53\% of the cases the observed effect was positive, meaning that the initially happiest people lived longer. In $13 \%$ the effect of happiness appeared to be negative, happy people living shorter lives. In $34 \%$ of the cases the difference was not statistically significant.

At first glance this does not denote a robust effect. Yet a more consistent picture emerges when we make a difference between studies among ailing people and studies among healthy populations. There is also a difference to be found in the results of short-term and long-term follow-up studies.

\subsubsection{Happiness and longevity in sick people}

Eleven follow-up studies have been done among ailing people, partly among frail elderly and partly among patients suffering serious diseases. Given the poor health of these people, the follow-up period was typically no longer than a few years. These studies are presented in Table 1 in order of follow-up length; the shortest follow-up period was 1 year, the longest 11 years. 


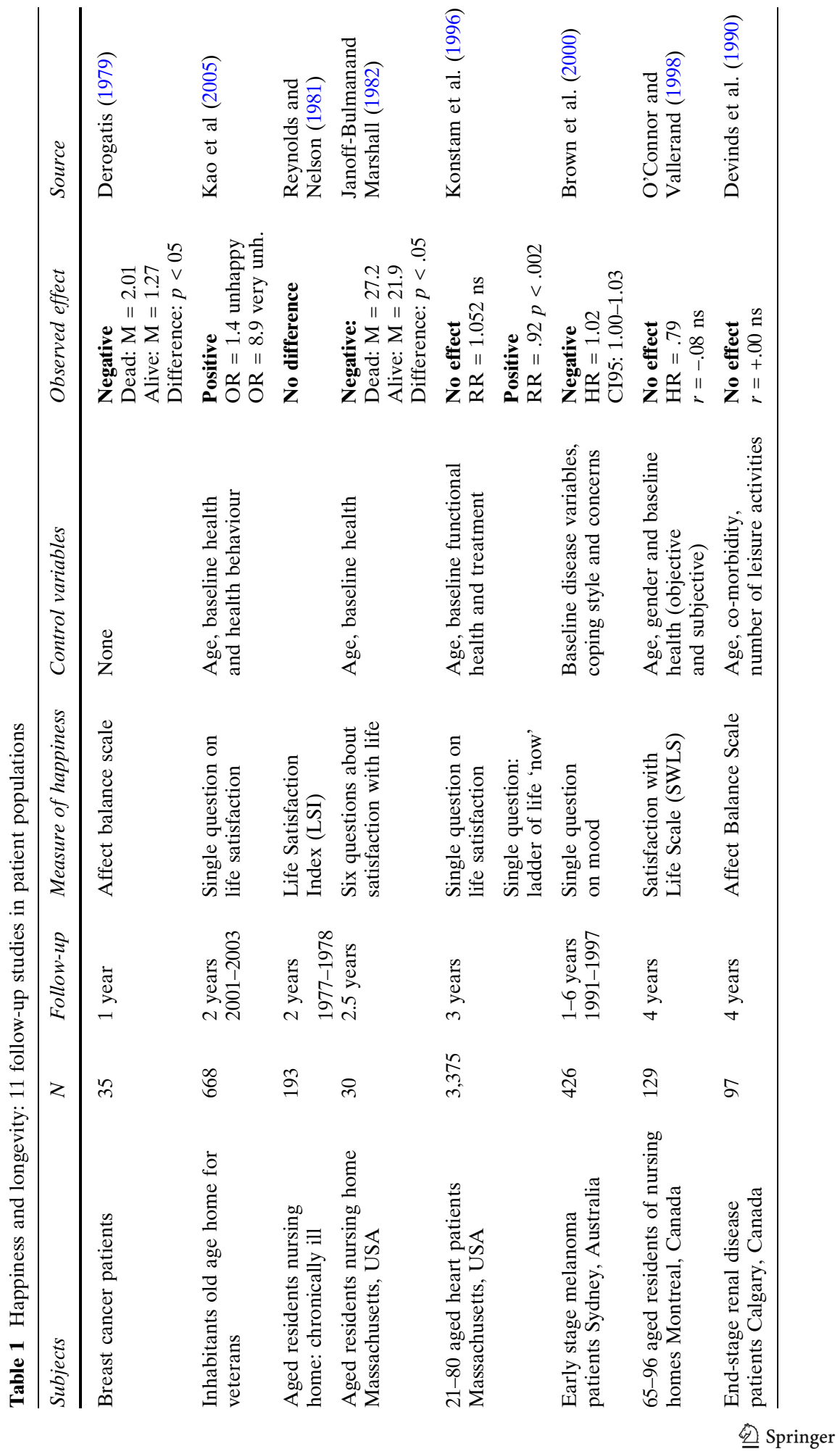




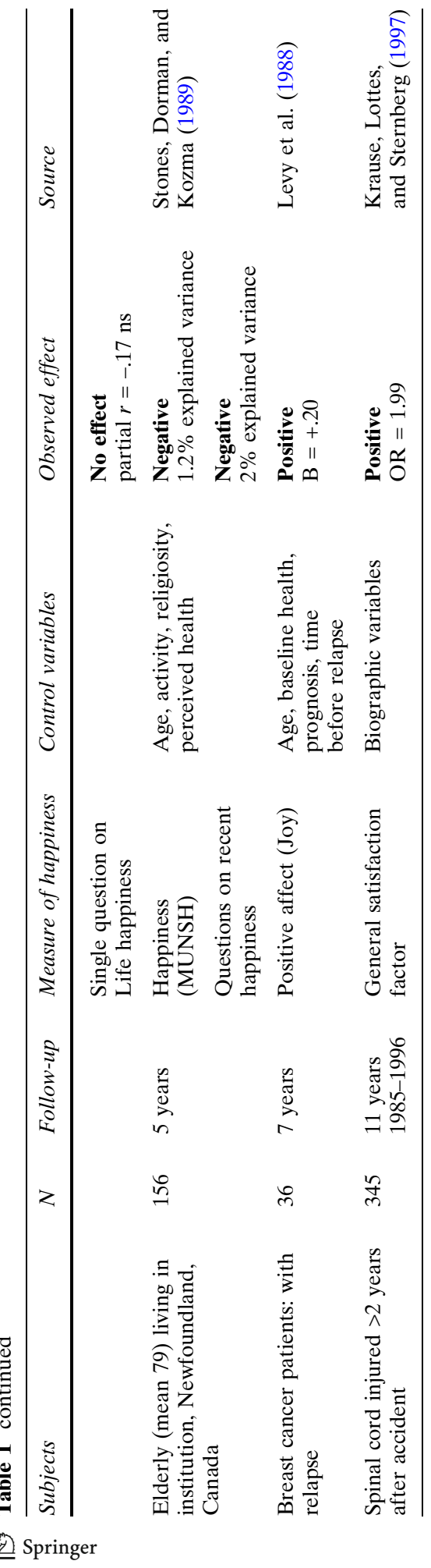


Researchers in these 11 studies observed 14 effects, of which only four appear to be positive and five negative, while in another five cases no significant effect was found. The positive effects were observed in studies with relatively healthy samples, that is, veterans in an old age home (not a nursing home), heart patients of all ages and people with spinal cord injuries. An exception to this pattern was the positive effect found for cancer patients that had a relapse. The negative effects were observed among incurably ill patients and the very old frail elderly.

Together these results do not suggest that happiness 'heals', at least not that happiness can restore health in the case of serious illness. In other words: happiness does not appear to prolong the deathbed.

\subsubsection{Happiness and longevity in healthy populations}

Nineteen follow-up studies in healthy populations are summarized in Table 2, mainly non-institutionalized elderly persons and a few studies among younger age categories. A special case is the study carried out among nuns, summarized at the bottom of Table 2. The studies are again presented in order of length of the followup period, which vary from 1 year to more than 60 years. Five of the studies cover 20 years or more.

Researchers in these 19 follow-up studies assessed 24 effects, of which 16 were positive, while in eight cases an observed (positive) effect did not reach statistical significance. In the case of the study done in Japan by Kawamoto and Doi (2002) the non-significance is possibly due to control for activity and social contacts, which is likely to have removed variance in happiness. None of the studies in Table 2 resulted in a negative effect.

The observed positive effects of happiness on longevity are quite sizable and amount to 7.5 years and 10 years. The strongest effect was observed in the longest follow-up, the study among American nuns, which covered their entire adult lifetime. In this study, happiness in young adulthood was measured using autobiographies written by the nuns on entering the convent. Unfortunately baseline health could not be controlled in that study. In the study by Levy et al. among over 50 aged in Ohio USA, the researchers did control baseline health and still found that the happy lived 7.5 years longer.

It is not possible to generalize these finding to a simple statement such as: happy people live so many years longer. This is partly due to technical problems such as the use of incomparable statistics and different cut-off points between more and less happy people. Another problem is that the size of the effect may differ across subgroups of a population, such as among age categories. Still it clear that the effect of happiness on longevity is large. It involves several years and as such is comparable to the effect of smoking or not.

Since we have seen that happiness does not cure serious illness, this outcome means probably that happiness 'protects' one against falling ill. That interpretation fits well with the fact that the effects manifest most strongly in the long-term studies.

\subsection{How could happiness protect physical health?}

This begs the question of how happiness might protect against illness. Several possible mechanisms are mentioned in the literature. 


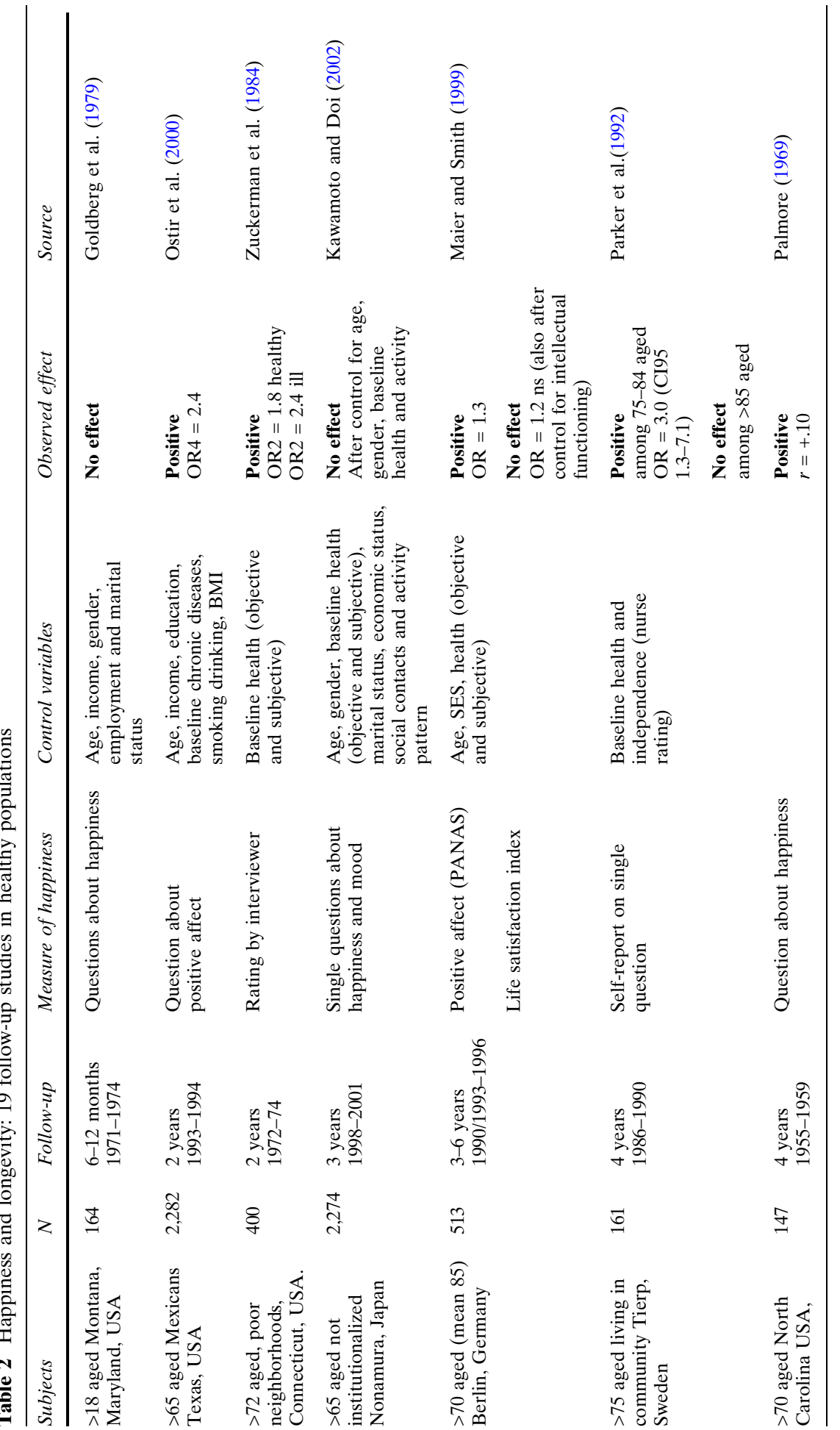




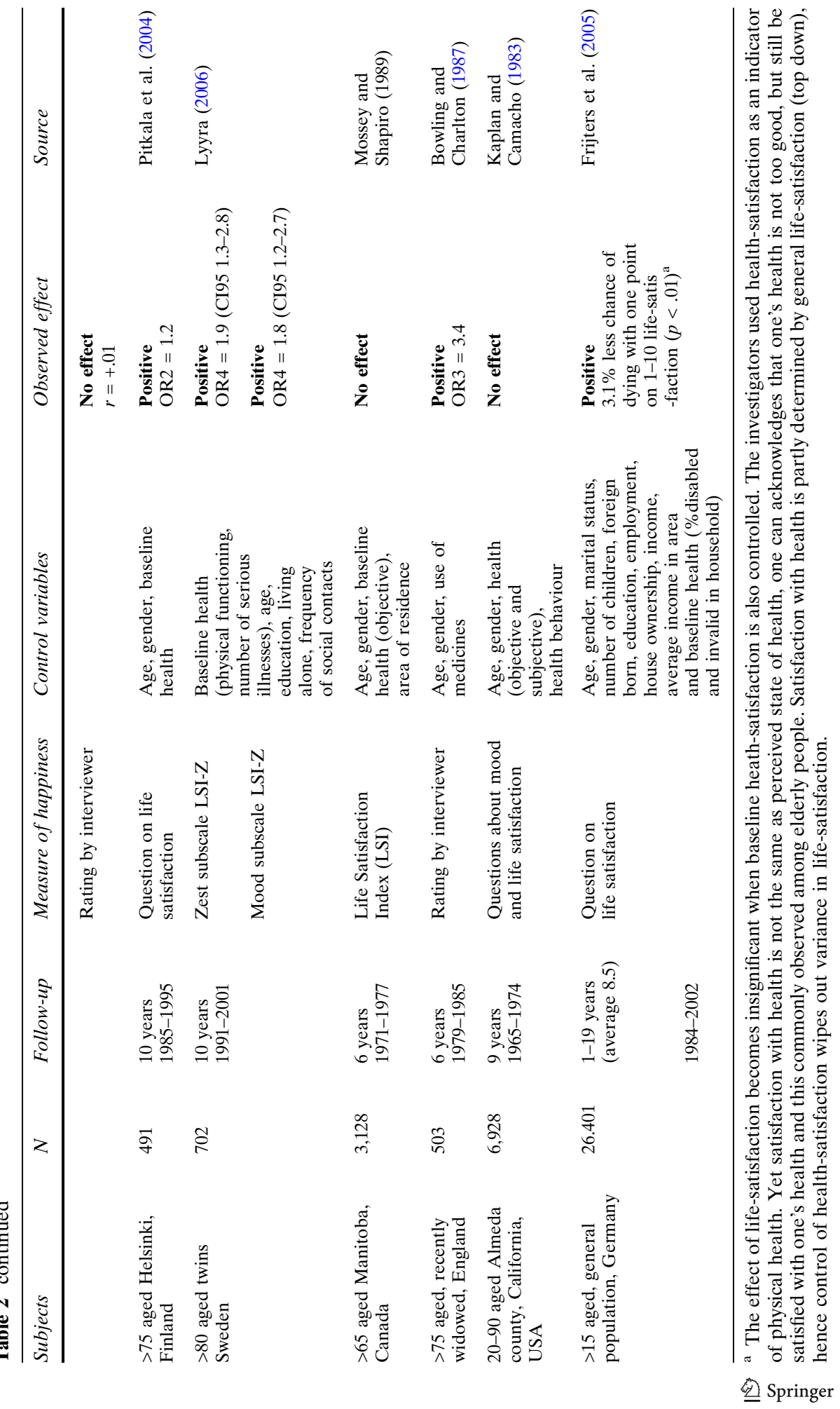




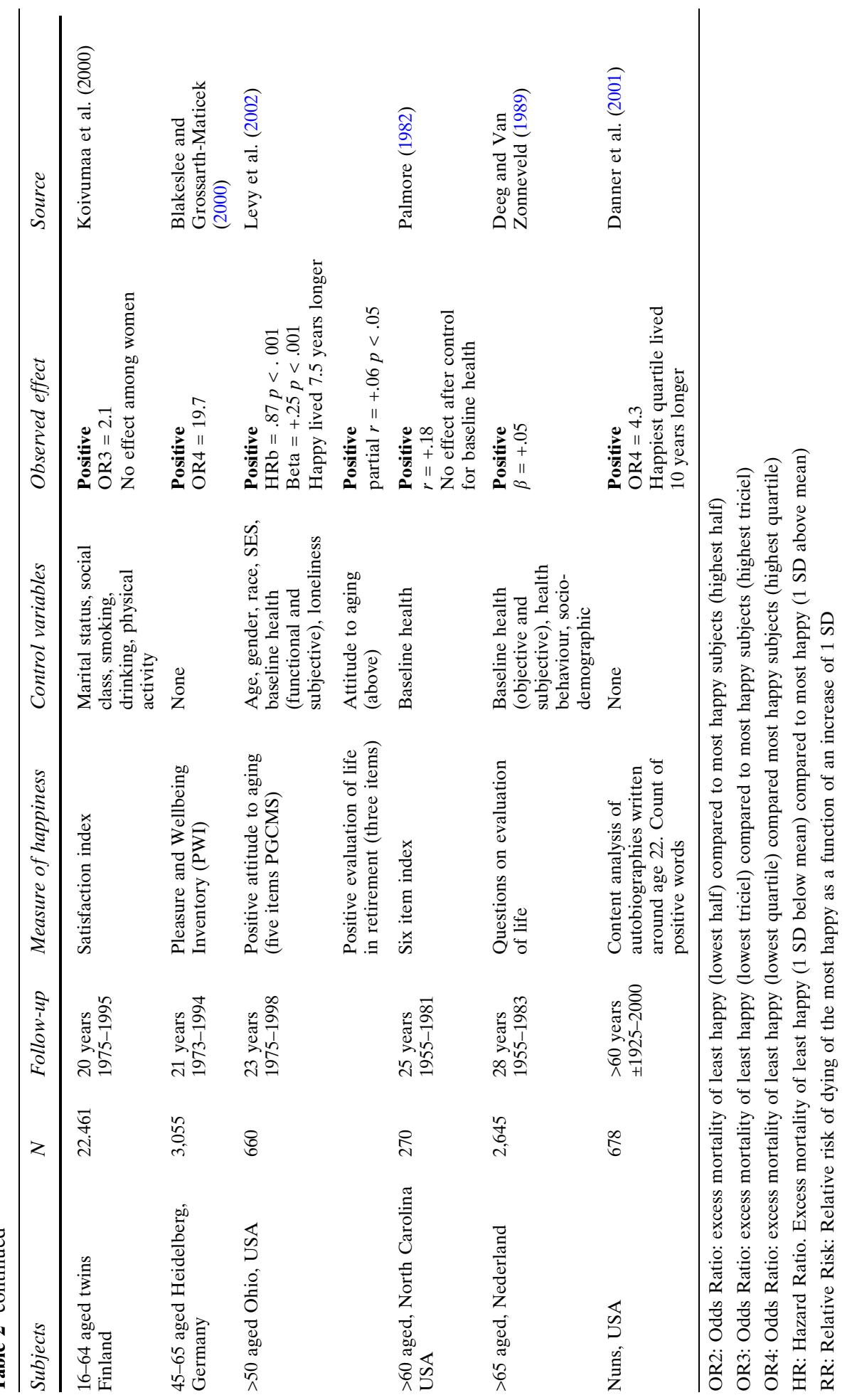


The most commonly mentioned direct effect is that chronic unhappiness activates the fight-flight response, which is known to involve harmful effects in the long run, such as higher blood pressure and a lower immune response. The effect of negative mental states is well documented in psychosomatic medicine. There are also indications that positive mental states protect against illness, e.g. better immune response when in good mood (Cohen et al., 1995).

Another commonly mentioned mechanism is better health behavior. Happy people are more inclined to watch their weight (Schulz, 1985, p. 52), are more perceptive of symptoms of illness (Ormel, 1980, p. 350) and cope better with threatening information (Aspingwall \& Brunhart, 1996). Happy people also live healthier, they engage more often in sports (Schulz, 1985) and they tend to be more moderate with smoking and drinking (Ventegodt, 1997, pp. 180-184).

Happiness could also further health through its wider activating effects, which keep the body fit and resilient. The reverse is seen in depression that typically slows down functioning and probably for that reason makes people more susceptible to illness. This mechanism fits Frederickson's (1998) theory that positive affect 'broadens' the action repertoire. According to Frederickson, positive affect helps also to 'build' resources and this is likely to create healthier living conditions. One notable mechanism in this context is that happiness facilitates the creation and maintenance of supportive social networks.

Another mechanism may be that happy people make better choices in life, because they are more open to the world and more self-confident. Happy people are also less likely to fall victim to the pattern of one-dimensional thinking in distress, which might hamper choice (Zautra, 2003).

There is piece-meal evidence for each of these causal mechanisms, but as yet little overview on their relative importance and interactions. For the time being we know that happiness fosters physical health, but not precisely how.

\section{Implications for preventive health care: An exploration}

This finding that happiness adds to health opens new ways for health promotion, preventive public health care in particular. It implies that we can make people healthier by making them happier. This not only broadens the practical options for interventions, but also widens the ideological basis for health promotion, the goal of 'Health for all' coinciding with the utilitarian aim of 'Greater happiness for a greater number'.

What innovations could this approach lead to? To answer this question I will first summarize the commonly used ways to promote public health. Next I consider to what extend these policies also add to happiness; in other words, I look how much synergy there is between current health promotion and the requirements for greater happiness. Using this as a basis, I then identify in section "Furthering health through happiness" some ways that can be used to further happiness that are not yet part of public health policy.

\subsection{Spearheads of preventive health care}

Preventive health care operates at different levels, at the micro-level of individual citizens, at the meso-level of social institutions and at the macro-level of nations. 
At the level of individuals, illness is prevented by means of inoculation programs and by providing periodical health checks for categories such as new-borns and school children. Next there are attempts to raise awareness of health treads via health education, common themes of which today are that we should take more physical exercise, stop smoking, drink moderately, eat healthy and have safe sex.

At the level of institutions health policy is aimed at reducing disease-producing conditions in the work and living environment. The emphasis is on regulations, for instance rules for safety in working places, hygiene in restaurants and sewage systems in cities. The observance of such rules is enforced by controls, i.e. fines for noncompliance or the closing down of building sites. Adherence is also encouraged by providing information.

At the level of nations public health is also protected in several ways, such as by keeping people with infectious diseases out of the country, preventing pollution with noxious chemicals and mandatory safety controls of food and consumer commodities. Health protection is also an issue in wider policies. For instance one of the objectives of social security schemes is to prevent health damage resulting from (child) poverty.

It is hard to say how effective each of these policies is, but together they seem to contribute substantially to public health. Life expectancy doubled in the last century and is still rising and this gain is at least partly due to public health policies (VanderMaas, 1989).

\subsection{Fit with pursuit of greater happiness for a greater number}

These improvements in physical health are likely to contribute to happiness, though as we have seen above, the effects of health on happiness are typically small. Does preventive health care otherwise add to happiness? Let us consider the possible effects at each of the levels discussed here.

\subsubsection{Healthy lifestyle and happiness}

It is not likely that inoculation programs and health screenings will have an independent effect on happiness. However, it is possible that life-style education has. It could be that a healthy life-style is more enjoyable irrespective of its add-on physical health, e.g. that taking regular exercise makes life more satisfying anyway. However it is also possible that healthy living is not particularly enjoyable and that health educators typically try to make us do things that we do not like. What do the available data tell us?

Physical exercise Sportive people tend to be somewhat happier than non-sportive people, and the difference appears to be independent of age, marital status and physical health (Schulz, 1985). There are indications of a causal effect, in particular the effects of jogging on mood (Biddle, 2000). In this case there is synergy between the promotion of health and happiness

Smoking Moderate smokers appear to be no less happy than non-smokers, but heavy smokers are. There are indications for a causal effect of happiness on smoking, a follow-up among American adolescents showing that earlier unhappiness predicts later smoking (Bachman, O' Malley, \& Johnson, 1978), but in a recent follow-up in Russia, happiness appeared not to predict starting or stopping smoking (Graham, Eggers, \& Sukhatankar, 2004, p. 18). The available data do not tell us whether 
smoking cuts back on happiness irrespective of health. So, for the time being, we cannot rule out the possibility that smoking affect health negatively but happiness positively, hence we are not sure that synergy exists on this point.

Drinking Moderate drinkers appear to be happier than teetotallers, the optimum being one or two units of alcohol a day (Ventegodt, 1995, pp. 180-184). As in the case of smoking, heavy drinkers are less happy, that is people who drink five or more units of alcohol per day. The only indication of causality is found in a five-year follow-up in Russia, in which an increase in drinking appeared to be associated with a decline of happiness. Unfortunately the amounts of alcohol involved are not reported (Graham et al., 2004). As in the foregoing case we cannot rule out that heavy drinking may be worse for your health than for your happiness. Only in the case problem drinking is there a clear synergy.

Eating There is a lot of research into the effects of nutrition on physical health, but hardly any research into the effects of diet on happiness. Analysis of a health-survey in the Netherlands showed no relationship between intake of unhealthy food-stuffs (sugar, fats) and happiness, nor with healthy food (fruit), while consumption of meat and dairy-products was slightly positively correlated with happiness (Aakster, 1972). In a study carried out in Denmark the researcher observed that people who often eat fast foods tend to be somewhat less happy (Ventegodt, 1995). In both cases the correlations could be spurious or be due to a causal effect of happiness on food preference rather than the converse. There is not much research either on the effects of how much one eats on happiness. The available data suggest that being slightly overweight does not depress happiness, people with Body Mass Index between 25 and 30 being happiest (Ventegodt, 1995, pp. 232-234). Yet again we lack data on cause and effect. All in all, no clear synergy has been found as yet.

\subsubsection{Healthy living environment and happiness}

At the institutional level preventive healthcare deals primarily with physical aspects of the living environment, such as proper sewage, removal treatment, providing clean air and standards that must be met for electrical appliances or that detail what constitutes safe stairways. Does this also add to happiness? There is a correlation between quality of housing and happiness, independent of marital state and social class (World Database of Happiness, Correlational findings on Happiness and Living environment, Veenhoven, 2006b). Causality is probable, but not proven as yet. The same holds for working conditions, though we know a lot about the effects of working conditions on health, we are still largely in the dark about the effects of working conditions on happiness.

\subsubsection{Sane society and happiness}

At the societal level an important spearhead of preventive health care is the control of infectious diseases in the country. This will certainly add to public health, but is unlikely to involve an independent effect on happiness. Another aim is to reduce of accidents in road traffic and workplaces. In this case synergy is more likely, since comparative research has shown a strong negative correlation between mortality from accidents and average happiness (Veenhoven, 1996, p. 34). Causality is likely, but not proven as yet; the correlation can also be due to a greater degree of accident proneness in unhappy countries. 
As noted above, considerations of health also play a role in wider social policies such as social security arrangements. Contrary to common expectation, there appears to be no relationship between spending on social security and health outcomes in nations, nor a relationship with happiness (Veenhoven, 2000a). So in this case there is again no synergy.

All in all, it is clear that not all health promotions are likely to further happiness as well. As yet this seems to be the case only for policies that aim at promoting exercise and preventing problem drinking and accidents. This applies to policies that aim at physical health. Synergy may be greater for preventive mental health care.

\section{Furthering health through happiness}

Because happiness adds to physical health, health can also be furthered by policies that make people happier in the first place. What policies can we think of? Below are some proposals for each of the three levels discussed above.

\subsection{Helping individuals to live happier}

Happiness can be furthered at the individual level by (1) information (2) training and (3) guidance. This approach is particularly useful in modern nations, where the environmental conditions are typically so good that most of the variance in happiness is due to individual differences.

\subsubsection{Evidence-based happiness advice}

Happiness depends to some extent on the choices we make in life, in particular in modern 'multiple-choice societies'. Life-choices are for the most part based on expected happiness, for instance we typically choose a profession we think we will like. Economists call this 'expected utility', or 'decision utility', and acknowledge that this may differ from later 'experienced utility', because decisions are mostly made on the basis of incomplete information. An example of mal-informed choice is the decision to accept a higher paying job that requires more commuting. People typically accept such jobs in the expectation that the extra money will compensate for the travel time, but follow-up research has shown that they are mostly wrong, and that happiness tends to go down in such cases (Frey, 2004).

Research of this kind can help people to make more informed choices. Though there is no guarantee that things will pan out in the same way for you, it is still useful to know how it has worked out for other people in the recent past. Such research is particularly useful if it concerns similar people.

This policy does not involve paternalism; it does not push people into a particular way of life, but it provides them with information for making a well-informed autonomous decision. Paternalism would only be involved if research is manipulated or its results communicated selectively. For instance if the observed negative effect of parenthood on happiness is disguised (World Database of Happiness, Correlational findings on happiness and Having Children, Veenhoven, 2006b).

This approach to the furthering of happiness is similar to current evidence based health-education. As in the case of happiness, we are often not sure about the consequences of life-style choices on our health. How much drinking is too much? Is 
eating raw vegetables really good for your health? We cannot answer such question on the basis of our own experience and common wisdom is often wrong. Hence we increasingly look to the results of scientific studies that provide us with ever more information.

As yet, the information basis for such a way of furthering happiness is still small. Although there is a considerable body of research on happiness, this research is typically cross-sectional and does not inform us about cause and effect. What we need is panel data that allow us to follow the effects of life-choices over time. Still another problem is that current happiness research deals mainly with things over which we have little control, such as personality and social background. What we need is research on things we can choose, for example, working part-time or fulltime or raising a family or not.

Once such information becomes available, it will quickly be disseminated to the public, though the lifestyle press and the self-help literature. It can also be included in organized health-education, broadened to become education for 'living well'. The problem is not in the dissemination of knowledge, but in the production of it.

\subsubsection{Training techniques for art-of-living}

Happiness depends heavily on various skills for living, such as realism, determination, social competence and having some resilience. Consequently, improving such skills can further an individual's happiness.

As yet, such attempts focus typically on repairing skill-deficits, for instance psychotherapy in case of unrealistic beliefs and empowerment trainings for sub-assertive individuals. Many of the interventions are provided in the context of mental health care and are often paid for by health insurers. This supply caters to the unhappiest part of the population. Recently there has also been a rise in techniques that aim at to strengthen the life-skills of people without problems, in particular the 'Positive Psychology' movement (Seligman \& Csikszentmihalyi, 2000). There is less institutional support for such 'positive training', but the potential audience is much greater.

In this context it would be worthwhile to invest in the development of training that focus on the art of living. 'Art-of-living' is the knack of leading a satisfying life, and in particular, the ability to develop a rewarding life-style (Veenhoven, 2003). This involves various aptitudes, some of which seems to be susceptible to improvement using training techniques. Four of these aptitudes are: (1) the ability to enjoy, (2) the ability to choose, (3) the ability to keep developing and (4) the ability to see meaning.

Learning to enjoy The ability to take pleasure from life is partly in-born (trait negativity-positivity), but can to some extent be cultivated. Learning to take pleasure from life was part of traditional leisure-class education, which emphasized prestigious pleasures, such as the tasting of exquisite wines and the appreciation of difficult music. Yet it is also possible to develop an enjoyment of the common things in life, such as breakfast or watching the sunset. Training in savoring simple pleasures is part of some religious practices.

Hedonistic enjoyment is valued in present day modern society and figures prominently in advertisements. Yet techniques that help us to gain the ability to enjoy are underdeveloped. There are no professional enjoyment trainers, at least no trainers aiming at improving our general level of enjoyment. There is professional 
guidance for specific types of pleasures, such as how to appreciate fine arts and often the main goal is to sell a particular product.

Still it would seem possible to develop wider enjoyment training techniques. One way could be to provide training in 'attentiveness', possibly using meditation techniques. Another option could be the broadening of one's repertoire of leisure activities, which could link up with expertise in various stimulation programs. A third way could be looking at ways to remove inner barriers to enjoy, which could be linked to clinical treatment of a-hedonie.

Learning to choose As mentioned above, happiness depends also the choices one makes in life and hence also on one's ability to choose. The art-of-choosing involves several skills.

One such skill is getting to know what the options are. This aptitude can be improved by learning and this is one of the things we do in consumer education. Expertise in this field can be used for training in the charting of wider life options.

Another requirement is an ability to estimate how well the various options would fit one's nature. This requires self knowledge and that is also something that can be improved, self-insight being a common aim in training and psychotherapy.

Once one knows what to choose, there is often a problem of carrying through. This phase requires aptitudes such as perseverance, assertiveness and creativity, all of which can be strengthened and are in fact common objectives in vocational trainings.

The next step in the choice process is assessing the outcomes, in term of the above-mentioned distinction, assessing whether 'expected utility' fits 'experienced utility'. This phase calls for openness to one's feelings and a realistic view on one's overall mood pattern. Training in mood monitoring is common practice in psychotherapy and could possibly be improved using computed based techniques of experience sampling.

The problem is not so much to develop such training techniques, but to separate the chaff from the corn. That will require independent effect studies. Once such techniques have been proven to be effective a market will develop.

Learning to grow Happiness depends largely on the gratification of basic needs, and an important class of needs is 'growth-needs' (Maslow, 1954), also referred to as 'functioning needs' or 'mastery needs'. These needs are not restricted to higher mental functions but also concern the use and development of the body and senses. In animals, the gratification of these needs is largely guided by instinct, but in humans it requires conscious action. Cultures typically provide standard action-patterns for this purpose, such as providing for vocational career scripts or artistic interests but people must also make choices of their own, in particular in multiple-choice societies. Failure to involve oneself in challenging activities may lead one into diffuse discontent or even depression, this for example happens regularly after retirement from work. Thus another art-of-living is to keep oneself going and developing.

Intervention would also seem possible in this case. Mere information will probably be useful and one can also think of various ways to get people going. Once again training techniques can build on available experience, in this case experience in various activation programs. There is already an ample supply of 'growth trainings' on the peripheries of psychology but as yet little evidence for the effectiveness of such interventions and certainly no proof of long term effects on happiness. 
Helping to see meaning Probably, but not certainly, happiness also depends on one seeing meaning in one's life. Though it is not sure that we have an innate need for meaningfulness as such, the idea of it provides at least a sense of coherence. Seeing meaning in one's life requires that one develops a view of one's life and that one can see worth in it. These mental knacks can also be strengthened and possible one can also learn to live with the philosophical uncertainties that surround this issue. There is experience on this matter in existential counseling and in practices such as 'lifereviewing' (Holahan, Holahan, \& Wonacott, 1999) and 'logo-therapy' (Frankl, 1946). As far as I know, the impact of such interventions on happiness has yet to be investigated.

\subsubsection{Professional life-counseling}

If we feel unhealthy we go to a medical general practitioner, who makes a diagnosis and either prescribes a treatment or refers us to a medical specialist. If we feel unhappy, there is no such generalist. We have to guess about the possible causes ourselves and on that basis consult a specialist who may be a psychologist, a marriage counselor or a lawyer. Professional guidance for a happier life is unavailable as yet. This is a remarkable market failure, given the large number of people who feel they could be happier.

The size of the demand is reflected in the booming sales of self-help books and the willingness to pay for things that promise greater happiness, such as cosmetic surgery and second homes. The main reason is probably that the knowledge basis for such a profession is still small and that trust in happiness counseling is undermined by the many quacks operating in this area.

Still there seems to be a future for professional counseling for a happier life and for related life coaching and trainings. There is demand for such services, but as yet no proper supply. Much can be gained by developing that supply. One of the ways is to stimulate the professionalization of current activities in that area, amongst other things by following people who use such services to establish what interventions add to happiness or do not. The development of professional life counseling could also profit from the above-advised research into long-term changes in happiness following major life-choices.

\subsection{Improving the livability of institutions}

Happiness depends further on environmental factors, amongst which the residential conditions in which we live and the organizational context in which we work or get educated.

There is a lot of research on residential preferences but amazingly little research into the effects of residential conditions on happiness. Research is driven by the wish to sell and the focus is therefore on expected utility rather than on experienced utility. As a result, there is as yet no solid evidence base for promoting happiness at the local level and decision making is still dominated by mere beliefs.

We find more research in the field of work organization, in particular a considerable body of literature on job-satisfaction. Yet job-satisfaction does not always coincide with life-satisfaction and this literature leaves us largely in the dark about cause and effect. There is also a large literature on the negative effects of workconditions, such as professional injuries and burnout, but this literature is largely blind for positive effects. As a result there is as no good evidence base for happiness 
promotion in this field either. The same holds for schools. We know a lot about the exam results produced by educational institutions, but hardly anything about their impact on long-term happiness.

\subsection{Improving the livability of society}

Happiness also depends on the macro-social conditions in which one lives and in this case we can build on a better evidence base. Comparative research has revealed wide differences in average happiness across nations, scores on a $0-10$ step scale ranging from 8.2 in present day Denmark to 3.2 in Tanzania (Veenhoven, 2005). There is a clear pattern in these differences. About $83 \%$ of the variation in average happiness can be explained by 'hard' country characteristics, such as economic development, political democracy and rule of law (Veenhoven \& Kalmijn, 2005, p. 436). What do these data tell us about the possibilities to create greater happiness for a greater number?

Material wealth People live happier in rich countries than in poor countries, the correlation between average happiness and buying power per head is +.66 ! The relationship is not linear, but follows a pattern of diminishing returns. Growth in material wealth adds little to happiness once the buying power per head is more than $\$ 10.000$ per year. So, economic development adds most to happiness in poor countries.

Political democracy People also live happier in democratic countries. The correlation is less strong in this case $(r=+.43)$, but follows a linear pattern, suggesting that happiness can also be advanced by further democratization in already democratic countries. This deduction is supported by the fact that in democratic and happy Switzerland happiness appears to be highest in the cantons where the threshold for referenda is lowest (Frey \& Stutzer, 2000).

Freedom Likewise, people live happier in free countries. This holds for three kinds of freedom: economic freedom, political freedom and freedom in the private sphere of life. Economic freedom appears to be most important for happiness in poor nations and private freedom in rich nations (Veenhoven, 2000b). The relationship is again linear, suggesting that the saturation point has not yet been reached in the present day world.

Governance Comparative research has also revealed that happiness prospers in wellgoverned countries. There are strong correlations with rule of law $(r=+.53)$ and government effectiveness $(r=+.60)$. These relationships are largely independent of economic development and appear in all regions of the world (Ott, 2006).

This all suggests that greater happiness for a greater number can be achieved by policies that aim at a decent material standard of living, the fostering of freedom and democracy and good governance. 


\section{Conclusions}

Happy people live longer, probably because happiness protects physical health. If so, public health can be furthered by policies that aim at greater happiness of a great number. Current public health policies seem only to affect happiness marginally.

Happiness can be advanced in several ways: At the individual level happiness can be furthered by means of (1) providing information about consequences of life-choices on happiness, (2) training in art-of-living skills, and (3) professional life-counseling. At the level of society greater happiness for a greater number can be achieved by policies that aim at a decent material standard of living, the fostering of freedom and democracy and good governance.

Evidence based happiness engineering requires more research.

\section{References}

Aakster, C. W. (1972). Socio-cultural variables in the etiology of health disturbances: A sociological approach. PhD dissertation, University of Groningen, The Netherlands.

Aspinwall, L. G., \& Brunhart, S. M. (1996). Distinguishing optimism from denial: Optimistic beliefs predict attention to health threads. Personality and Social Psychology Bulletin, 22, 993-1003.

Bachman, J. G., O'Malley, P. M., \& Johnson, J. (1978). Youth in transition vol. IV: Adolescence to Adulthood, change and stability in the lives of young men. Ann Arbor, USA: University of Michigan, Institute for Social research.

Biddle, S. J. (2000). Emotions, mood and physical activity. In S. J. Biddle, R. K. Fox, \& S. H. Boutcher (Eds.), Physical activity and psychological well-being. London: Routledge.

Benyamini, Y., Leventhal, E. A., \& Leventhal, H. (1999). Self-assessments of health. What do people know that predicts their mortality. Research in Aging, 21, 477-500.

Blakeslee, T. R., \& Grossarth-Maticek, R. (2000). Feelings of pleasure and well-being as predictors of health status 21 years later. http://www.attitudefactor.com

Bowling, A. P., \& Charlton, J. (1987). Riskfactors for mortality after bereavement: a logistic regression analysis. Journal of the Royal College of General Practitioners, 37, 551-554.

Brown, J. E., Butow, P. N., Culjak, G., Coates, A. S., \& Dunn, S. M. (2000). Psychosocial predictors of outcome: time to relapse and survival in patients with early stage melanoma. British Journal of Cancer, 83(11), 1448-1453.

Chiriboga, D. A. (1982). Consistency in adult functioning; the influence of stress. Ageing and Society, 2, 7-29.

Cohen, S., Doyle, W. J., Skomer, D. P., Fireman, P., Gwaltney, J. M., \& Newson, J. P. (1995). State and trait negative affect as predictors of subjective and objective symptoms of respiratory viral infections. Journal of personality and Social Psychology, 68, 159-169.

Danner, D. D., Friessen, W. V., \& Snowdon, D. A. (2001). Positive Emotion in early life and longevity: findings from the nun study. Journal of Personality and Social Psychology, 80, 804813.

Deeg, D. J., \& Van Zonneveld, R. (1989). Does happiness lengthen life? In R. Veenhoven (Ed.), How harmful is happiness? Consequences of enjoying life. (pp. 29-43). Rotterdam: University Press Rotterdam.

Derogatis, L. R., Abeloff, M. D., \& Melisaratos, N. (1979). Psychological coping mechanisms and survival time in metastatis breast cancer. JAMA, 242(14), 1504-1508.

Devins, G. M., Mann, J., Mandin, H., Paul, L. C., Hons, R. B., Burgess, E. D., Taub, K., Schorr, S., Letourneau, P. K., \& Buckle, S. (1990). Psychosocial predictors of survival in end-stage renal disease. Journal of Nervous and Mental Disease, 178(2), 127-133.

Frankl, V. E. (1946). De zin van het bestaan, een inleiding tot de logotherapie. Nederlandse vertaling, Donker 2002, Rotterdam.

Frederickson, B. L. (1998). What good are positive emotions? Review of General Psychology, 2, 300319. 
Frey, B. S. (2004). Economic consequences of mis-predicting utility. Working Paper, Institute for Empirical Research in Economics, Zürich, Switzerland.

Frey, B. S., \& Stutzer, A. (2000). Happiness prospers in democracy. Journal of Happiness Studies, 1, 79-102.

Friedman, H. S., Tucker, J. S., Tomlinson-Keasey, C., Schwartz, J. E., Wingard, D. L., \& Criqui, M. H. (1993). Does childhood personality predict longevity? Journal of Personality and Social Psychology, 65, 176-185.

Frijters, P., Haisel-DeNew, J., \& Shields, M. A. (2005). Socio-economic status, health shocks, life satisfaction and mortality: Evidence from an increasing mixed proportional hazard mode. Discussion paper IZA DP 1488, Institute for the Study of Labour, Bonn, Germany.

Goldberg, E. L., Comstock, G. W., \& Hornstra, R. K. (1979). Depressed mood and subsequent physical illness. American Journal of Psychiatry, 136, 530-534.

Graham, C., Eggers, A., \& Sukhatankar, S. (2004). Does happiness pay? An exploration based on panel data from Russia. Economic Behavior and Organization, 55, 319-342.

Hawkins, D. N., \& Booth, A. (2005). Unhappily ever after: Effects of long-term, low-quality marriages on well-being. Social Forces, 84, 452-471.

Helliwell, J. F. (2002). How's life? Combining individual and national variables to explain subjective wellbeing. Economic Modeling, 20, 331-360.

Holahan, C. K., Holahan, C. J., \& Wonacott, N. L. (1999). Self appraisal, life satisfaction and retrospective life choices across one and three decades. Psychology and Aging, 14, 238-244.

Janoff-Bulman, R., \& Marshall, G. (1982). Mortality, wellbeing and control: a study of institutionalized aged. Personality and Social Psychology Bulletin, 8(4), 691-698.

Kaplan, G. A., \& Camacho, T. (1983). Perceived health and mortality: a nine-year follow-up of the human population laboratory cohort. American Journal of Epidemiology, 117, 292-304.

Kawamoto, R., \& Doi, T. (2002). Self-reported functional ability predicts three-year mobility and mortality in community dwelling older persons. Geriatrics and Gerontology International, 2, 6874.

Kao, S., Lai, K. L., \& Lin, H. C. (2005). WHOQOL-BREF as predictors of mortality: A two-year follow-up study at veteran homes. Quality of Life Research 14, 1443-1454.

Konstam, V., Salem, D., Pouleur, H., Kostis, J., Garkin, L., Shumaker, S., Mottard, I., Woods, P., Konstam, M., \& Yusef, S. (1996). Baseline quality-of-life as a predictor of mortality and hospitalization in 5,035 patients with congestive heart failure. American Journal of Cardiology, 78, 890-895.

Krause, J. S., Lottes, S., \& Sternberg, M. (1997). Mortality after spinal cord injury: An 11-year prospective study. Archives of Physical Medicine and Rehabilitation, 78, 815-821.

Levy, S. M., Bagley, C., Lee, J., \& Lippman, M. (1988). Survival Hazard analysis in first recurrent breast cancer patients: seven-year follow-up. Psychosomatic medicine, 51, 520-528.

Levy, B. R., Slade, M. D., Kunkel, S. R., \& Kasl, S. (2002). Longevity increased by positive selfperceptions of aging. Journal of Personality and Social Psychology, 83(2), 261-270.

Lyubomirsky, S., Diener, E., \& King, L. (2005). The benefits of frequent positive affect: Does happiness lead to success? Psychological Bulletin, 3005, Vol. 131, pp. 803-855.

Lyyra, T. M. (2006). Predictors of mortality in old age contribution of self-rated health, physical functions, life satisfaction and social support on survival among older people. Jyväskylä: University of Jyväskylä.

Maier, H., \& Smith, J. (1999). Psychological predictors of mortality in old age. Journals of Gerontology. Series B, Psychological Sciences and Social Sciences, 54, 44-54.

Maslow, A. H. (1954). Motivation and personality. NY, USA: Harper.

Mossey, J. M., \& Shapiro, E. (1982). Self-rated health: a predictor of mortality among the elderly. American Journal of Public Health, 72, 800-808.

O’Connor, B. P., \& Vallerand, R. J. (1998). Psychological adjustment variables as predictors of mortality among nursing home residents. Psychology and Aging, 13(3), 368-374.

Ostir, G. V., Black, S. A., Goodwin, J. S., \& Markides, K. S. (2000). Emotional well-being predicts subsequent functional independence and survival. Journal of the American Geriatric Society, 48, 473-478.

Ormel, J. (1980). Moeite met leven of een moeilijk leven? Groningen: Konstapel.

Ott, J. (2006). Good governance and happiness in nations. Paper presented at the conference of the International Society for Quality of Life Studies, July 2006, Grahamstown, South Africa.

Palmore, E. B. (1969). Physical, mental and social factors in predicting longevity. Gerontologist, 9 , 103-108. 
Palmore, E. B. (1977). Change in life satisfaction; a longitudinal study of persons aged 46-70. Journal of Gerontology, 32, 311-316.

Palmore, E. B. (1982). Predictors of longevity difference. The Gerontologist, 22, 513-518.

Parker, M. G., Thorslund, M., \& Nordstrom, M.-L. (1992). Predictors of mortality for the oldest old: A 4-year follow-up of community-based elderly in Sweden. Archives of Gerontology and Geriatry, 14, 227-237.

Pitkala, K. H., Laakkonen, M. L., \& Strandberg, T. E. (2004). Positive life orientation as a predictor of 10-year outcome in an aged population. Journal of Clinical Epidemiology, 57, 409-414.

Reynolds, D.K., \& Nelson, F. L. (1981) Personality, life satisfaction and life expectancy. Suicide and Life Threatening Behavior, 11, 99-110.

Seligman, M. E., \& Csikszentmihalyi, M. (2000). Positive psychology: an introduction. American Psychologist, 55, 5-14.

Schulz, W. (1985). Lebensqualität in Österreich (Quality of Life in Austria). Report Institut für Soziologie der Sozial- und Wirtschaftswissenschaftliche Fakultät der Universität Wien, 1985, Vienna, Austria.

Seedhouse, D. (1996). Health promotion: Philosophy, prejudice and practice. UK: Chichester, Wiley.

Stones, M. J., Dorman, B., \& Kozma, A. (1989). The prediction of mortality in elderly institution residents. Journal of Gerontology: Psychosocial Sciences, 44(3), 72-79.

VanDam, F. (1989). Does happiness heal? In R. Veenhoven (Ed.) How harmful is happiness? Consequences of enjoying life or not (pp. 17-23). The Netherlands: Universitaire Pers Rotterdam.

Van derMaas, P. (1989). Kan Nederland gezonder? In R. Veenhoven (red), Kan Nederland gelukkiger? (pp. 11-29). The Netherlands: Universitaire Pers Rotterdam.

Veenhoven, R. (1984). Conditions of happiness. Dordrecht, The Netherlands: Kluwer Academic.

Veenhoven, R. (1996). Happy life-expectancy: A comprehensive measure of quality-of-life in nations. Social Indicators Research, 39, 1-58.

Veenhoven, R. (2000a). Wellbeing in the welfare state, level not higher, distribution not more equitable. Journal of Comparative Policy Analysis: Research and Practice, 2, 91-125.

Veenhoven, R. (2000b). Freedom and happiness: A comparative study in 44 nations in the early 1990s. In E. Diener \& E. M. Suh (Eds.), Culture and subjective well-being (pp. 257-288). Cambridge, USA: MIT Press.

Veenhoven, R. (2003). Arts of living. Journal of Happiness Studies, 4, 373-384.

Veenhoven, R. (2005). Average happiness in 90 nations in the early 2000s. World Database of Happiness, Distributional Findings in Nations, Rank report 2005/1 http://worlddatabaseofhappiness.eur.nl/hap_nat/findingreports/.

Veenhoven, R. \& Kalmijn, W. (2005). Inequality-adjusted happiness in nations. Egalitarianism and utilitarianism married together in a new index of societal performance [Special issue on 'Inequality of happiness in nations']. Journal of Happiness Studies, 6, 421-455.

Veenhoven, R. (2006a). Gezond geluk. Effecten van geluk op gezondheid en wat dat kan betekenen voor de preventieve gezondheidszorg. Verkenningstudie in het kader van het programma 'Gezond leven' van ZonMw, January 2006.

Veenhoven, R. (2006b). World Database of Happiness: Continuous register of scientific research on subjective appreciation of life. Erasmus University Rotterdam. Available at http://worlddatabaseofhappiness.eur.nl.

Ventegodt, S. (1997). Livskvalitet og omsteandigheder tidligt I livet. Forknigscenter for Livskvalitet, Kobenhaven, Denmark.

Warburton, D. M. (Ed.) (1994). Pleasure: The politics and reality. UK: Wiley, Chichester.

Warburton, D. M., \& Sherwood, N. (Eds.) (1996). Pleasure and quality-of-life. UK: Wiley, Chichester.

Zautra, A. J. (2003). Emotions, stress and health. Oxford NY, USA: Oxford University Press.

Zuckerman, D. M., Kasl, S. V., \& Ostfeld, A. M. (1984). Psychosocial predictors of mortality among the elderly poor. American Journal of Epidemiology, 119, 410-423. 